2015-12-09

\title{
Digital Energy Networks: A Post Occupancy Evaluation and Appraisal of an Intelligent Low Energy Lighting System
}

\author{
Anthony Colohan \\ Technological University Dublin, anthony.colohan@tudublin.ie \\ Joseph Teehan \\ Technological University Dublin, joseph.teehan@tudublin.ie \\ Keith Sunderland \\ Technological University Dublin, keith.sunderland@tudublin.ie
}

See next page for additional authors

Follow this and additional works at: https://arrow.tudublin.ie/archastrocon

Part of the Electrical and Electronics Commons

\section{Recommended Citation}

Colohan, A. et al. (2015). Digital Energy Networks: A Post Occupancy Evaluation and Appraisal of an Intelligent Low Energy Lighting System. In: UPEC (ed.) 50th International Universities Power Engineering Conference (UPEC 2015). Staffordshire University, Stoke on Trent IEEE.

This Conference Paper is brought to you for free and open access by the Archaeoastronomy Research at ARROW@TU Dublin. It has been accepted for inclusion in Conference Papers by an authorized administrator of ARROW@TU Dublin. For more information, please contact arrow.admin@tudublin.ie, aisling.coyne@tudublin.ie,gerard.connolly@tudublin.ie.

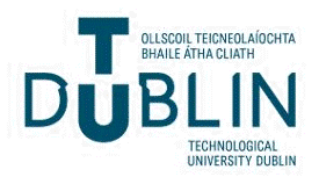




\section{Authors}

Anthony Colohan, Joseph Teehan, Keith Sunderland, Martin Barrett, and James Preston 


\section{Digital Energy Networks: A Post Occupancy Evaluation and Appraisal of an Intelligent Low Energy Lighting System}

\author{
Anthony Colohan \\ Dublin Institute of Technology, \\ Ireland \\ Anthony.Colohan@dit.ie \\ Dr. Martin Barrett \\ Dublin Institute of Technology, \\ Ireland \\ Martin.Barrett@dit.ie
}

\author{
Joseph Teehan \\ Dublin Institute of Technology, \\ Ireland \\ Joseph.Teehan@dit.ie
}

\author{
Dr. Keith Sunderland \\ Dublin Institute of Technology, \\ Ireland \\ Keith.Sunderland@dit.ie \\ Jimmy Preston \\ Scott Group, \\ Ireland \\ ipreston@scottgroup.ie
}

\begin{abstract}
-
The reduction in the electrical power requirements of LED lighting and the coinciding advancements in digital technology have now enabled luminaires to be powered and controlled exclusively over safety extra low voltage (SELV) wiring systems. The implementation of LED luminaires powered via a centralised 48 Volt DC low-latency communication network, with the capability to gather real-time data, has provided the potential to yield considerable electrical energy savings within a building. This paper will present an appraisal of this technology and will examine the technologies potential to make electrical energy savings, improve the quality of lighting and achieve cost savings on an electrical distribution system within a building environment. The intelligent low voltage lighting system was tested in a controlled environment and the energy reduction methods employed in an existing installation over one year provided a further reduction in energy consumption compared to the system's original settings. Furthermore, the ability of the system to enhance the buildings intelligence, in terms of monitoring space utilisation, traffic patterns and temperature.
\end{abstract}

Index Terms- Intelligent lighting, power density, electrical services, daylight harvesting, building energy rating.

\section{INTRODUCTION}

Electric lighting is paramount to the existence of today's 24 hour lifestyle, lighting helps us see and perform the essential visual tasks we take for granted throughout our daily lives. The built environment and society is reliant on sufficient levels of artificial lighting to enhance the performance of visual tasks, facilitate sporting and recreational activities whilst also improving the safety on our streets and within the workplace. In the UK, artificial lighting consumes around 58,000GWh each year which amounts to approximately $20 \%$ of all the electricity generated [1] and non-domestic lighting is estimated to be responsible for the production of 24 million tonnes of Carbon Dioxide per year [2].

The generation, transmission and distribution of AC mains electrical energy to facilitate artificial lighting in our buildings accounts for significant energy losses, these inefficiencies may be attributed to a centralised fossil fuel generating plant operating at an efficiency of $35 \%$ whilst an additional $10 \%$ loss can also be accrued to power losses in the conductor resistance and reactance of transmission and distribution lines. Further energy losses are incurred due to the conversion of electrical energy into light with the majority of the electrical energy converted to heat rather than light reducing the overall efficiency of the process. The waste of energy is exacerbated even further across the summer months by the demand for air conditioning plant to cool the space as a result of heat gains emitted through the conversion of electrical energy to light.

With the global energy demand set to double by 2030[3] the emphasis of energy conservation within the built environment could not be more prevalent today. The amount of electrical energy consumed by a building's artificial lighting scheme is a function of three key components: luminous efficacy (lumens/Watt), the duration that the installed luminaires are left switched on and the electrical demand of control gear. The implementation of simple lighting control techniques such as presence detection and the adoption of good lighting design practice have proved effective in achieving significant energy savings. Previous studies have revealed energy savings of up to $50 \%$ may be achieved [4].

However, any attempt to save energy by compromising on the visual comfort of a building with a scant lighting design is destined for failure. The basis of energy efficient lighting is to provide the right amount of light, in the right place, at the right time with the right lighting equipment [5]. The advent of solid-state lighting (SSL) and the introduction of an intelligent centralised SELV DC power and control system has afforded the opportunity to implement advanced control techniques which can now provide individual luminaire daylight harvesting, fine grained dimming, occupancy control and temperature sensing. The benefits of this system include improved energy savings, reduced electrical containment and labour costs, easy modifications, a safer electrical system and much less maintenance over the life span of the installation. This paper will examine and evaluate the Redwood Intelligent 
Low Energy Lighting System as a viable alternative to traditional lighting systems which embrace advanced control methods as means of saving energy and improving the quality of lighting within the space.

\section{ELECTRICAL SERVICES IN BUILDINGS}

Hitherto, almost all artificial lighting installations within buildings were predominately powered via a 230 Volt AC mains supply with some means of control added, the most primitive form of control being the basic ON-OFF switching of luminaires. Lighting installations which cater far more for the dynamic needs of its occupants whilst potentially providing energy savings tended to opt for an overlay lighting system. Wired overlay systems comprise of a mains 230 Volt AC supply to power the luminaires and a separate (SELV) signal to communicate with daylight and occupancy sensors for the purpose of control and monitoring. In order to accommodate this type of dual wiring system compliance with local wiring regulations must be adhered too. Protective separation of wiring systems of SELV and PELV circuits from the live parts of other circuits, which have at least basic insulation, shall be achieved by one of the following arrangements [6]:

- SELV and PELV circuit conductors enclosed in a non-metal sheath or insulating enclosure in addition to basic insulation

- $\quad$ SELV and PELV circuit conductors separated from conductors of circuits at voltages higher than Band I by an earthed metal sheath or earthed metal screen

- Circuit conductors at voltages higher than Band I may be contained in a multi-core cable or other grouping of conductors provided the SELV and PELV conductors are insulated for the highest voltage present

- The wiring systems of other circuits are in compliance with Regulation 412.2.4.1

- Physical separation or segregation of different wiring voltage systems such as the SELV and PELV.

These wiring constraints add to the complexity and cost of the installation, in most cases special containment consisting of two or three separate compartments divided by a physical divider or fillet needs to be fabricated in order to accommodate both wiring systems. These types of electrical wiring systems are time consuming to install and lack flexibility when future modifications are required. The total costs including labour and material associated with the installation of $100 \times 100 \mathrm{~mm}$ galvanised steel trunking are estimated to be in the region of $£ 31.24 / \mathrm{m}$ [7]. Inherently labour costs are inflated by the need for qualified electricians to install the containment and wiring system. A traditional lighting installation with low voltage controls is shown in Fig. 1.

The electrical distribution system supplying a building's artificial lighting installation can provide excessive levels of overcurrent on the occurrence of a short circuit or overload. All electrical conductors intended to carry alternating current within an installation depend on circuit protective devices to disconnect the supply and safely interrupt excessive levels of fault current in the shortest possible time so that the amount of let through energy that the faulty circuit is exposed to is kept to a minimum. Electrical designers are compelled to satisfy that coordination between circuit protective devices and the installation's circuit conductors is assured; this entails selecting adequate size conductors and specifying suitable protective devices so that the electrical installation is safeguarded in event of a fault arsing based on (1) and (2).

$$
\begin{aligned}
& I_{B} \leq I_{n} \leq I_{Z} \\
& I_{2} \leq 1.45 \times I_{Z}
\end{aligned}
$$

Another characteristic that the designer of low voltage (LV) circuits must address is that the terminal voltage of the connected appliances does not suffer from under-voltage as a result of the selection of inadequate sized cables and excessive lengths of cable run. The circuit conductor's resistance is inversely proportional to its cross sectional area and proportional to its length. Each conductor incurs a voltage drop $(\mathrm{mV})$ for every ampere of design current (A) that passes through every metre of the conductor's length $(\mathrm{m})$. The $(\mathrm{mV} / \mathrm{A} / \mathrm{m})$ value for any particular electric conductor is obtained in the IEE wiring regulations seventh edition, Appendix 4.

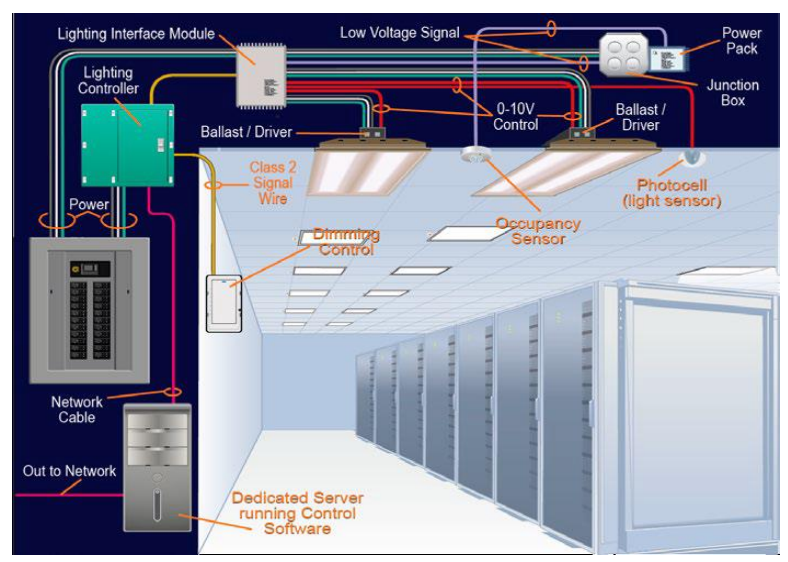

Fig. 1. A traditional artificial lighting installation incorporating low voltage $230 \mathrm{~V}$ and SELV 0-10V control system for a building.

\section{POWER OVER ETHERNET}

Lighting circuits connected to the electrical public supply should not experience a volt drop in excess of $3 \%$ of the rated supply voltage; to ensure this value is not exceeded; electrical designers are limited by the length of run and the size of cable they can specify. The eminent arrival of light emitting diodes (LED) to the market has given rise to a new dawn in energy efficient lighting and SELV control systems. The innate DC quality of LED lighting eradicates the need for a 230 Volt AC supply to power the luminaires.

In 2003, Power over Ethernet (PoE) was developed to deliver power and data down the same Ethernet cable for a 
host of devices which require DC current. Although not, specifically designed for LED lighting, the PoE technology was initially devised to distribute power from a centralised AC/DC rectification unit to VoIP telephones, network hardware and PCs. The earliest PoE standard IEEE 802.3af allowed for the delivery of a maximum of $350 \mathrm{~mA}$ per port via a 44 - $57 \mathrm{~V}$ DC supply [8]. Further developments to increase the current capabilities has given rise to the release of the 2009 PoE standard IEEE 802.3at which increased the current output to a maximum of $600 \mathrm{~mA}$ per port [9]. A four pair PoE standard IEEE 802.3bt 4PPoE was proposed. Since then Cisco systems have made efforts to endorse a purpose built, universal PoE product that can deliver a maximum of $1200 \mathrm{~mA}$ using all four pairs in a Category 5e Ethernet cable as opposed to using only two of the pairs. The IEEE PoE based standards were not designed for optimizing the performance of LED lighting. In order for PoE based systems to support LEDs, a converter is required to be located near the LED luminaire which can vary the control current in response to the luminaire's dimming requirements. This approach has a detrimental effect on the efficiency of the PoE based system as a reduction in efficiency may be experienced between the PoE switch and the LED luminaire. These losses can be attributed to the DC/DC conversion that takes place near the luminaire and the requirement placed on the switch to maintain higher transmission power in order to accommodate the DC/DC conversion. Further $I^{2} R$ transmission losses occur as result of the increased conductor resistance that lend themselves to the two pair structured cabling system employed by the PoE based system.

The Redwood system (Fig. 2) is representative of an innovative intelligent lighting network that has applied suitable modifications to the existing PoE technology for the purpose of driving higher energy efficiencies in LED lighting, with a maximum of $700 \mathrm{~mA}$ per port (TABLE I). Redwood doubles-up on the conductor size by using a four pair system which in effect reduces the amount of power lost. In order to curtail the amount of transmission losses both systems limit the length of run of CAT5, CAT5e, CAT6 \& CAT6A cable to a distance of $100 \mathrm{~m}, 4.5 \mathrm{~W}$ per port may be lost over the cables resistance if this distance is exceeded.

TABLE I. PoE 802.3 - Cisco - CommScope Redwood System

\begin{tabular}{|c|c|c|c|c|c|}
\hline & $\begin{array}{c}\text { IEEE } \\
\text { Parameters } \\
\text { PoE }\end{array}$ & $\begin{array}{c}\text { IEEE } \\
802.3 \mathrm{at} \\
\text { PoEP }\end{array}$ & $\begin{array}{c}\text { Proposed } \\
\text { IEEE } \\
802.3 \mathrm{bt} \\
4 \mathrm{PPoE}\end{array}$ & $\begin{array}{c}\text { Cisco } \\
\text { UPOE }\end{array}$ & $\begin{array}{c}\text { Redwood } \\
\text { System }\end{array}$ \\
\hline $\begin{array}{c}\text { Output } \\
\text { current, } \\
\text { normal } \\
\text { mode } \\
\text { (mAdc) }\end{array}$ & $\begin{array}{c}350 \\
(\max )\end{array}$ & $\begin{array}{c}600 \\
(\max )\end{array}$ & tbd & $\begin{array}{c}1200 \\
(\max )\end{array}$ & $\begin{array}{c}700 \\
(\max )\end{array}$ \\
\hline $\begin{array}{c}\text { Pairs } \\
\text { required for } \\
\text { current } \\
\text { capacity }\end{array}$ & $2-\mathrm{pr}$ & $2-\mathrm{pr}$ & $4-\mathrm{pr}$ & $4-\mathrm{pr}$ & $4-\mathrm{pr}$ \\
\hline
\end{tabular}

Notes: 4PPoE: 4-pair PoE

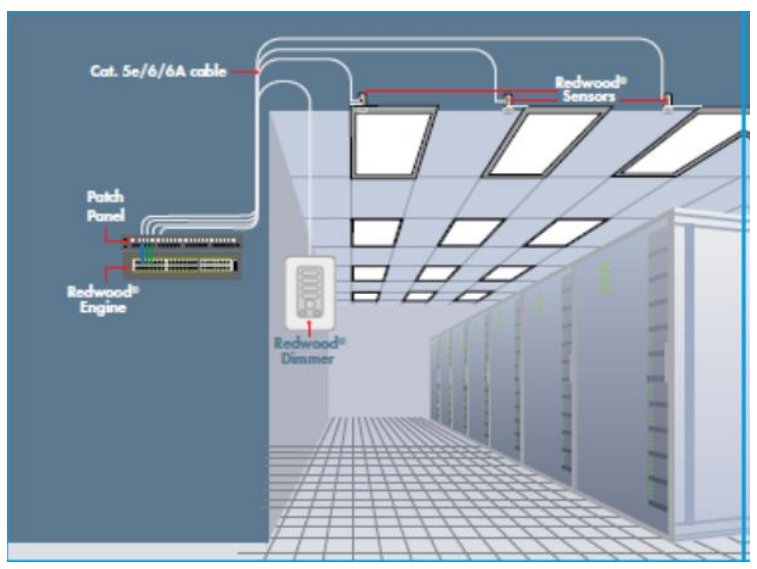

Fig. 2. SELV Intelligent Lighting Control System

\section{CONTROL OF THE LED LUMINAIRE}

The Redwood system is a centralised system that not only distributes power to its connected field devices and sensors but also handles the data communication traffic responsible for the control and monitoring of each of the LED luminaires.

Similar to the PoE based centralised switch, the third generation (3G) Redwood system comprises of 48 individual power/data ports that each have the capacity to deliver $34 \mathrm{~W}$ at a rated output voltage that ranges between $18-57.5 \mathrm{~V}$ DC. Each port can deliver between 100 - $700 \mathrm{~mA} \mathrm{[10]} \mathrm{depending}$ on the light output required from each of the LED luminaires connected to the engine. The Redwood system has a unique inbuilt electronic driver housed inside each port so that individual dimming control can be performed. This technique relieves the system of the unwanted field DC/DC conversion and transmissions losses that PoE based systems are exposed to.

There are two basic methods of controlling LEDs; Constant Current and Constant Voltage. The Redwood approved luminaires are designed to be controlled using Pulse Width Modulation (PWM). Constant current LEDs have two methods available for dimming purposes, PWM (Pulse Width Modulation) and Constant Current Reduction (CCR). The simplest form of dimming is the CCR method which delivers a continuous flow of DC current for a given level of light output. The level of light output is proportional to the level of current flowing through the LED. Hence, when the level of light output is to be dimmed the current is reduced accordingly.

PWM controls the dimming of LEDs by delivering bursts of current that range between 0 and the rated current of the LED, the LED is repeatedly switched from ON to OFF at a high frequency to create a square wave signal (Fig. 3). The duty cycle of this square wave signal determines the level of brightness of the LED, where the ratio between the LED ON time and the ON to OFF time dictates the percentage of light output from the LED. 


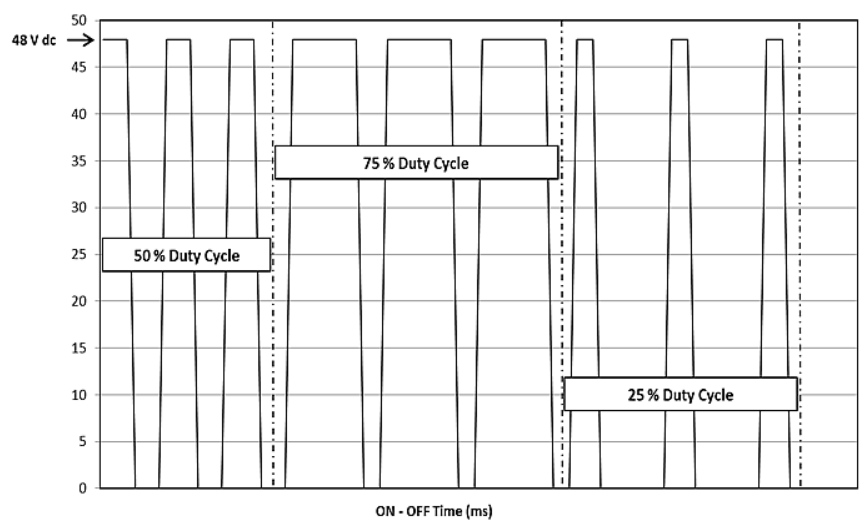

Fig. 3. Varying duty cycle of a PWM dimming control system, note the skewed nature of the switching cycles which are more realistic than an ideal square wave usually presented to demonstrate PWM.

The LED is switched from ON to OFF at such high frequencies that the resulting flickering is not perceptible to the human eye; all that is seen is a continuous flow of light with a reduced luminous intensity.

The electronic driver housed inside each port of the Redwood engine utilises the PWM (Pulse Width Modulation) technique to provide LED dimming. The nature of each type of LED is to exhibit a certain level of luminous intensity for a given rated current, unfortunately for dimming purposes the relationship between the rated current of an LED and its Colour Correlated Temperature (CCT) is not linear. Changes made to the rated current in order to adjust the level of light output could have a dramatic effect on the colour appearance of the LED, variations appearing in the colour of the LED become more noticeable when the level of light output is reduced to below $40 \%$, it is for this reason that PWM is the preferred option when large levels of dimming are required without comprising the chromaticity of the LED lighting scheme.

\section{BUILDING INTEGRATION}

The LED fixtures connected to the Redwood system each contain their own inbuilt occupancy, daylight level and temperature sensors. These sensors unlock the system's very own intelligent building sensor network. Real time data gathered and transmitted at speeds of $1 \mathrm{~kb} / \mathrm{sec}$ can provide an invaluable insight into the traffic patterns of the people using the building. Information captured by the LEDs' presence detection sensors can be shared across other platforms via the system's Application Programming Interface (API). The system can be configured to make decisions regarding space utilization within the building. Pre booked rooms which have not been occupied at the allocated times can be cancelled and made available electronically to all other users within the building.

The statistics pertaining to the buildings occupancy density will have a significant impact on the building energy use [11] Presence detection sensors not only provide a means to achieve energy efficient lighting but can divulge the necessary data to implement a more frugal building energy management regime and therefore a more efficient building. The information gathered can provide the answers to some significant questions regarding the overall energy efficiency within buildings for instance,

- Do the occupants use the specific small power equipment in the building intensely, or intermittently?

- How does the occupancy density vary across the day, week and year?

- What is the traffic pattern of the lifts and escalators within the building?

- Is thermal comfort in the required space being achieved?

\section{EXPERIMENTAL RESULTS}

The Intelligent Low Energy Lighting System's energy consumption was determined, initially, by setting up a test in a $12.5 \mathrm{~m}^{2}$ room and a south facing window, to determine the how the system performs using ON/OFF and Daylight Harvesting controls. Three dimmable Redwood Certified LED luminaires were installed in the suspended ceiling, $2.7 \mathrm{~m}$ above Finished Floor Level (FFL). An office desk, with a working plane of 0.74 metres above FFL with dimensions measuring $\mathrm{L} \times \mathrm{W}$ of $160 \mathrm{~cm} \times 78 \mathrm{~cm}$, was positioned in the centre of the room (Fig. 4).

Three points on the working plane were identified and a Lux meter was used to record three fixed luminance levels on the working plane. A wattmeter was also used simultaneously to record the power consumption, including the parasitic power, of the system. It should be noted that a parasitic power of $52.6 \mathrm{~W}$ was recorded and this value was subtracted from the wattmeter values to indicate the energy consumption of the three luminaires only.

In a typical Redwood installation a value of parasitic power would be apportioned to each luminaire. In the case of the second generation (2G) engine tested, which can accommodate 32 luminaires, this would mean that the $52.6 \mathrm{~W}$ would be divided by the number of luminaires connected to the engine (TABLE II). This represents a parasitic power value per luminaire of $1.65 \mathrm{~W}$.

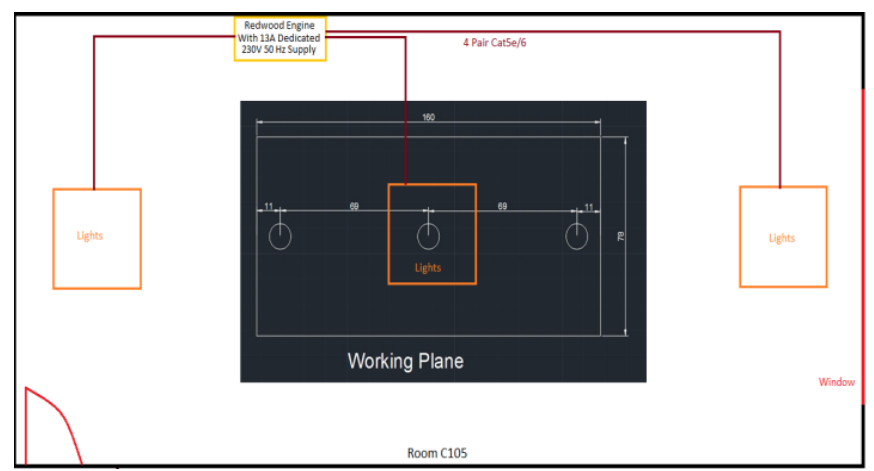

Fig. 4. Test room / desk layout of $12.5 \mathrm{~m}^{2}$ room with southern aspect window. 
TABLE II. Test room and desk layout artificial illuminance levels

\begin{tabular}{|c|c|c|}
\hline $\begin{array}{c}\text { Luminance } \\
\text { (lux) }\end{array}$ & $\begin{array}{c}\text { Redwood System } \\
\text { (\% Output) }\end{array}$ & $\begin{array}{c}\text { Power Consumed } \\
\text { (Watts) }\end{array}$ \\
\hline 200 & 71 & 38.8 \\
\hline 300 & 88 & 58.8 \\
\hline 400 & 100 & 75.5 \\
\hline
\end{tabular}

A model of the test room was created using IES-VE software. The FlucsPro application provided within IES-VE was used to simulate the artificial and daylight illuminance for the test room (Fig. 5). The simulation of the room model produced between 172 - 1235 lx using a Clear Sky model and 15 - 301 lx using an Overcast Sky model. The test was carried out on the $21^{\text {st }}$ of March at noon, the spring equinox.

Daylight luminance levels were recorded using a luxmeter to determine if the actual value of illuminance was adequate to light the working plane (TABLE III). The luxmeter results were recorded from three pre-determined points, over three days, on the office desk and an average taken of these values to produce an overall average illuminance on the working plane.
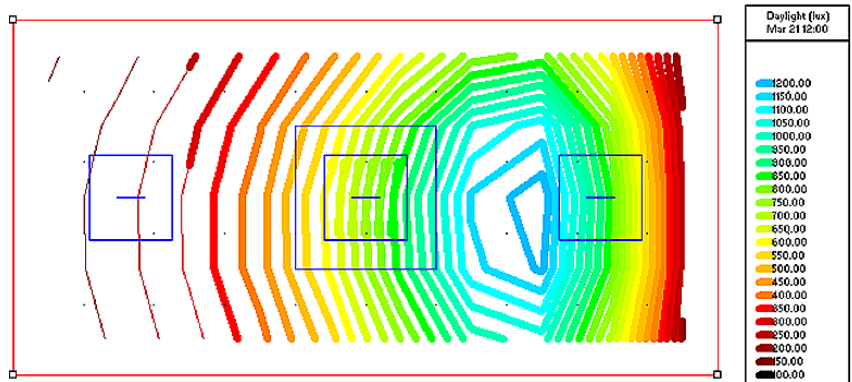

Fig. 5. Test room with daylight illuminance levels using IES-VE and FlucsPro artificial and daylight analysis application

TABLE III. Office desk daylight illuminance levels

\begin{tabular}{|c|c|c|c|c|c|}
\hline \multirow{2}{*}{ Date } & $\begin{array}{c}\text { Point } \\
\text { Left } \\
\text { (lux) }\end{array}$ & $\begin{array}{c}\text { Point } \\
\text { Centre } \\
\text { (lux) }\end{array}$ & $\begin{array}{c}\text { Point } \\
\text { Right } \\
\text { (lux) }\end{array}$ & $\begin{array}{c}\text { Average } \\
\text { (lux) }\end{array}$ & $\begin{array}{c}\text { Weather } \\
\text { Conditions }\end{array}$ \\
\hline $28 / 04 / 2015$ & 146 & 242 & 578 & 322 & Overcast \\
\hline $29 / 04 / 2015$ & 234 & 337 & 552 & 374 & Clear Sky \\
\hline $05 / 05 / 2015$ & 118 & 205 & 650 & 324 & Clear Sky \\
\hline
\end{tabular}

From these results it is clear that, during clear sky days, there was enough daylight entering the room and illuminating the working plane to justify daylight harvesting/dimming control of the LED luminaires. This simulation also provides a valuable insight for the need in building design to select appropriate types of glazing, the elevation from FFL in the exterior wall and the orientation of the windows for a building. Once daylight harvesting was activated, a number of profiles were set up using the proprietary management software to identify the most suitable lighting strategy for the room. Using a luxmeter, to determine if $300 \mathrm{~lx}$ is maintained on the working plane, an initial test was carried out to determine the overall power consumption. The output for all luminaires was set to $88 \%$, during which time inadequate levels of daylight were present, delivered a power density of $4.7 \mathrm{~W} / \mathrm{m}^{2}$. Subsequently, when individual luminaire sensors detected adequate daylight, the luminaires at the window and the centre of the room dimmed to $20 \%$ of output, delivering a power density of $2.18 \mathrm{~W} / \mathrm{m}^{2}$. Finally, another profile was developed for clear days such that the artificial lighting would gradually decrease as each luminaire was closer to the window. This was also tested and when adequate daylight was present in the room further energy reductions were achieved a power density of $1.31 \mathrm{~W} / \mathrm{m}^{2}$ (Table IV).

TABLE IV. Test room $\left(12.5 \mathrm{~m}^{2}\right)$ power consumption using daylight harvesting controls for the three luminaires with the illuminance level set to 300 lux. Parasitic power value of $1.65 \mathrm{~W}$ per luminaire is included in the values recorded using the wattmeter.

\begin{tabular}{|c|c|c|c|c|c|}
\hline Output of & \multicolumn{4}{|c|}{ Power (Watts) incl. Parasitic Power } & \multirow{2}{*}{$\begin{array}{c}\text { Power } \\
\text { Density } \\
W / \mathbf{m}^{2}\end{array}$} \\
\hline \multirow{2}{*}{$\begin{array}{l}\text { Inadequate } \\
\text { Daylight }\end{array}$} & $\begin{array}{l}\text { Wall } \\
88 \%\end{array}$ & $\begin{array}{c}\text { Centre } \\
88 \%\end{array}$ & $\begin{array}{c}\text { Window } \\
\mathbf{8 8 \%}\end{array}$ & Total & \\
\hline & 19.6 & 19.6 & 19.6 & 58.8 & 4.70 \\
\hline \multirow{2}{*}{$\begin{array}{l}\text { Adequate } \\
\text { Daylight }\end{array}$} & $\begin{array}{l}\text { Wall } \\
88 \%\end{array}$ & $\begin{array}{c}\text { Centre } \\
20 \%\end{array}$ & $\begin{array}{c}\text { Window } \\
20 \%\end{array}$ & Total & \\
\hline & 19.6 & 3.45 & 4.25 & 27.3 & 2.18 \\
\hline \multirow{2}{*}{$\begin{array}{c}\text { Further } \\
\text { Commissioning }\end{array}$} & $\begin{array}{l}\text { Wall } \\
\mathbf{5 0 \%}\end{array}$ & $\begin{array}{c}\text { Centre } \\
\mathbf{3 0 \%}\end{array}$ & $\begin{array}{c}\text { Window } \\
20 \%\end{array}$ & Total & \\
\hline & 7.75 & 4.25 & 4.35 & 11.4 & 1.31 \\
\hline
\end{tabular}

The IES-VE software was also used to simulate a larger room $\left(150 \mathrm{~m}^{2}\right)$, with southern aspect windows (Fig. 6). This room can accommodate 32 luminaires, indicative of a fully loaded Redwood $2 \mathrm{G}$ engine during normal operation. The resultant power density is $0.35 \mathrm{~W} / \mathrm{m}^{2}$ for parasitic power. Comparing this power density value to the National Calculation Methodology (NCM), which has a default value for power density of $0.57 \mathrm{~W} / \mathrm{m}^{2}$ [12] for parasitic power associated with Digitally Addressable Lighting controls, the Redwood 2G engine's parasitic power represents a $39 \%$ reduction.

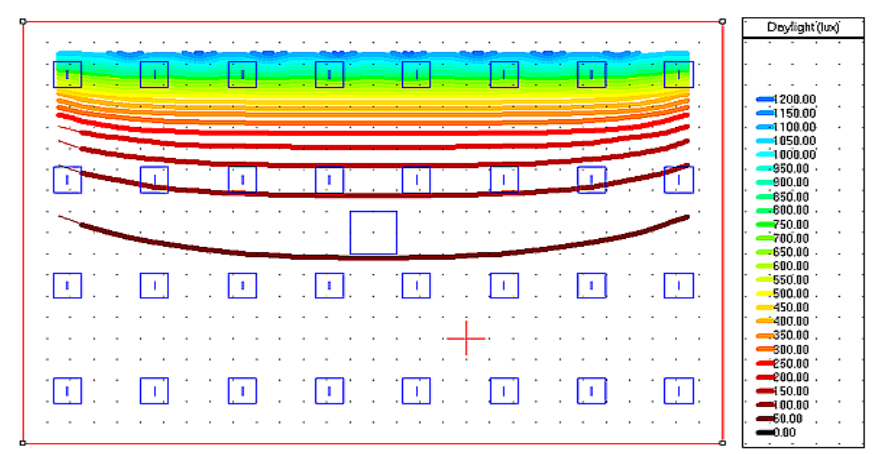

Fig. $6.150 \mathrm{~m}^{2}$ simulation room with daylight illuminance levels using IESVE and FlucsPro artificial and daylight analysis application. 
This simulation highlights that daylight harvesting control is only beneficial for the first $6 \mathrm{~m}$ from the exterior windows, or two out of the four rows of lighting in the room. This is another required parameter when using the NCM approach for building energy ratings.

The building observed for the post occupancy evaluation is a four storey building which consists of a total floor area (TFA) of $3390 \mathrm{~m}^{2}$. The building also contains a four storey internal atrium designed to avail of natural daylight. The area of interest during the evaluation was the first floor north wing consisting of $920 \mathrm{~m}^{2}$ containing two Redwood engines, 48 ports each, controlling $8327 \mathrm{~W}$ LED luminaires. The Redwood system recorded data over a 12 month period. At the initial date of installation, the power consumed was a peak of $1562.2 \mathrm{~W}$ including the parasitic power associated with two engines of $105.2 \mathrm{~W}$. This value of power is then converted to power density, based on (3).

$$
\text { Power Density }=\frac{\text { Power }}{\text { Area }} \mathrm{W} / \mathrm{m}^{2}
$$

Subsequently, the commissioning engineer, through an aggressive energy control strategy improved the energy performance from the initial power density value of 1.70 $\mathrm{W} / \mathrm{m}^{2}$ to $1.45 \mathrm{~W} / \mathrm{m}^{2}$ during the winter months and has recently achieved $0.83 \mathrm{~W} / \mathrm{m}^{2}$ (Fig. 7), a $>50 \%$ reduction in power density. All the changes made were in direct consultation with the client's facilities manager.

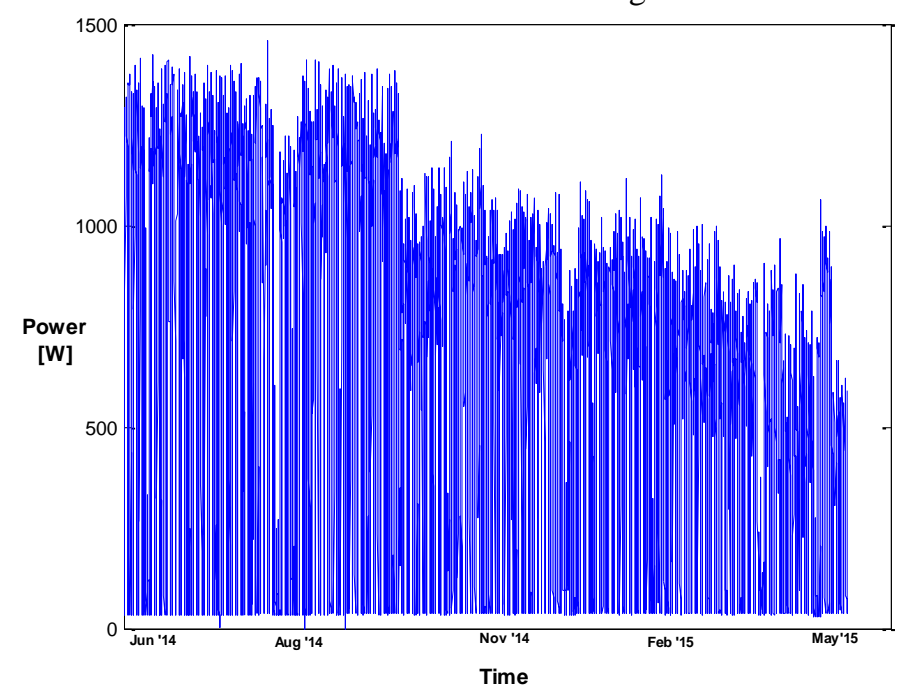

Fig. 7. The Redwood Management software screen display - electrical power consumption for $1^{\text {st }}$ floor north wing over one year period.

\section{CONCLUSION}

The testing of the Redwood system highlighted the ability of a 48 Volt DC low-latency communication network to provide accurate control and reductions in power density, which, as a consequence, will lead to lower costs associated with the energy consumption associated with artificial lighting.
Artificial lighting is traditionally dominated by AC mains voltage luminaires and is expensive to install due to the high associated containment and labour costs. Furthermore, the rigid approach associated with this traditional method offers little in the way of flexibility to building managers considering modifications to any office layout.

The PoE standards were designed to operate many different devices at SELV, a level which eliminates the requirement for an electrical engineer to carry out a lighting distribution design to comply with local electrical rules and regulations and qualified personnel to install the wiring.

The Redwood system optimizes the performance of PoE over a standard Ethernet cable to control LED luminaires.

This technique offers savings on installation and maintenance costs, a reduction in energy consumption by utilizing individual luminaire daylight harvesting control, presence detection and improved quality of light within the area where the system is installed.

The Redwood system topology offers individual luminaire control and temperature feedback to optimize visual and thermal comfort for the occupants of buildings. The data output of the Redwood system can be readily integrated with a building energy management system in such a way as to afford, facilities services within the building, a comprehensive overview of the building's performance and occupancy density.

\section{REFERENCES}

[1] Carbon Trust, "Energy Efficiency in Lighting - an overview", p6, 2003.

[2] Carbon Trust "How to Implement Lighting Controls Carbon Trust", p $1,2012$.

[3\} International Energy Agency, "Technology Roadmap: Smart Grids," http://www.iea.org/publications/freepublications/publication/smartgrids roadmap.pdf, 2011.

[4] Clanton \& Associates, Inc., D. Sanders and D. Chinnis, "A Life Cycle Cost Evaluation of Multiple Lighting Control Strategies" p2, 2011.

[5] P. Raynham. The Society of Light \& Lighting, "SLL Code for Lighting" p 124, 2012.

[6] IEE Wiring Regulations "Requirements for Electrical Installations" BS7671-2008 17th Edition, 2008.

[7] Spons "Mechanical and Electrical Services Price Book" Taylor \& Francis, p557, 2015.

[8] Power over Ethernet, IEEE Standard 802.3af, 2003

[9] Power over Ethernet enhancements, IEEE Standard 802.3at, 2009

[10] Commscope, "Data sheet for 3G Redwood engine", 2015.

[11] CIBSE "Evaluating operational energy performance of buildings at the design stage" TM54: 2013, p6, London, 2013

[12] BRE, "iSBEM User Guide, iSBEM version 4.1.e", Department Communities and Local Government, London, 2013. 